\title{
ESTUDO GEOAMBIENTAL DAS CONCENTRAÇÕES DE HIDROCARBONETOS DE PETRÓLEO (POLICÍCLICOS AROMÁTICOS - HPAs) AO LONGO DO RIO ESTRELA, BAÍA DE GUANABARA - RJ
}

\section{Geoenvironmental studies about concentrations of petroleum hydrocarbons (polylyclic aromatic - PAHs) along the Rio Estrela, Baía de Guanabara - RJ}

Carlos Marclei Arruda Rangel

Pós-Doutorando no Programa de Pós Graduação de Dinâmica dos Oceanos e da Terra da UFF Universidade Federal Fluminense, Departamento de Geologia / LAGEMAR - UFF marclei@igeo.uff.br

José Antônio Baptista Neto Doutor em Geografia Física pela Queen 'sUniversityof Belfast - UK. Professor Adjunto da Universidade Federal Fluminense - UFF jneto@igeo.uff.br

Estefan Monteiro da Fonseca Doutor em Geologia e Geofísica Marinha pela Universidade Federal Fluminense (UFF). Pós Doutorando no Departamento de Geologia/LAGEMAR - UFF oceano25@hotmail.com

Artigo recebido em 09/09/2012 e aceito para publicação em 05/12/2012

RESUMO Neste estudo, análises geoquímicas de dez amostras de sedimentos coletados ao longo do sistema fluvial do Rio Estrela, localizado ao norte da Baía de Guanabara, evidenciam a presença de impactos antropogênicos nesta área. As concentrações de hidrocarbonetos policíclicos aromáticos (HPAs) obtidas mostraram-se ligeiramente elevadas, quando comparadas com valores encontrados em ambientes naturais. Os HPAs foram analisados nos sedimentos ao longo da bacia do Rio Estrela. Embora as concentrações destes compostos detectados nesta área tenham ocorrido em baixas proporções, os tipos de HPAs detectados com alto peso molecular, são mutagênicos e carcinogênicos. Por esta razão, compreender a dinâmica de transporte, deposição e riscos ambientais dos HPAs para o sistema ecológico, especialmente para o sistema aquático, são importantes formas de monitoramento deste ambiente.

Palavras chaves: Rio Estrela, Baía de Guanabara, Poluição, HPAs

ABSTRACT In this study, the geochemical analysis of ten sediments samples collected along the fluvial system of the Estrela River, located in the northern portion of Guanabara Bay, shows the presence of anthropogenic impacts in this area. Concentrations of polycyclic aromatic hydrocarbons (PAHs) obtained were slightly higher when compared with values found in natural environments. The PAHs were tested in sediments along the drainage basin of Estrela River. Although the compounds found in this area have occurred in low proportions, PAHs compounds detected, with high molecular weight, are mutagenic and carcinogenic. For these reason, understanding PAHs transport, fate and environmental risk to ecological system, especially for aquatic ecosystem, are important forms of monitor this environment.

Keywords: Estrela River, Guanabara Bay, Pollution, PAHs 


\section{INTRODUÇÃO}

Os sedimentos fluviais apresentam constituintes minerais e orgânicos de origem natural ou antropogênicos que são ou podem tornar-se poluentes potenciais (Jaffé et al., 2003). Os poluentes introduzidos nos corpos aquosos tendem a se acumular em sedimentos, principalmente os de granulometria fina, devido à sua grande capacidade de adsorção (Hozales-Hoz et al., 2003).

Entre os poluentes orgânicos, os Hidrocarbonetos policíclicos aromáticos (HPAs) são comuns em ambientes aquosos, particularmente em sedimentos fluviais (Estèbe et al., 1997; Witt \& Trost, 1999; Yuan et al., 2001).

Embora possam estar naturalmente presentes nos ecossistemas, a contaminação por HPAs ocorre principalmente associada às atividades antropogênicas, que devido a este fator, são utilizados como marcadores. Os hidrocarbonetos poliaromáticos se constituem como uma classe de compostos orgânicos que variam em relação ao peso molecular, tornando possível distingui-los em duas classes de acordo com suas propriedades químicas, físicas e biológicas. HPAs que possuem de 2 a 3 anéis aromáticos em suas composições são de proveniência petrogênica. Estes são voláteis e possuem toxicidade aguda significativa aos organismos aquáticos, diferentemente dos HPAs constituídos de 4 a 7 anéis aromáticos que são derivados de combustão e não apresentam toxicidade aguda intensa (Boulobassi et al., 2005).

Com base nas informações supracitadas, considera-se de grande importância a compreensão da dinâmica dos HPAs, no que diz respeito aos processos de transporte, interação com o meio, destino e risco ambiental para os sistemas ecológicos, especialmente nos ambientes aquáticos (Shi et al., 2005).

O presente trabalho tem como objetivo a determinação e identificação de HPAs nas amostras de sedimentos da Bacia de drenagem do Rio Estrela, considerando a influência dos impactos da ocupação humana nesta área de estudo. Analisou-se também as características granulométricas e os teores de matéria orgânica nos sedimentos, assim como as particularidades de alguns parâmetros físico-químicos da água.

\section{ÁREA DE ESTUDO}

A Bacia do Rio Estrela se situa na região centro-sul do Estado do Rio de Janeiro, na porção norte da Baía de Guanabara (figura 1). A Baía de Guanabara é uma das maiores baias do litoral brasileiro. Possui uma área de aproximadamente $380 \mathrm{~km}^{2}$ com um espelho d'agua de $328 \mathrm{~km}^{2}$ em virtude de suas inúmeras ilhas. Sua bacia de drenagem mede cerca de $4000 \mathrm{~km}^{2}$ apresentando 45 rios e canais (Kjerve et al., 1997).

A Bacia hidrográfica do rio Estrela abrange quatro municípios do Estado do Rio de Janeiro: Miguel Pereira, pertencente à região do Médio Vale do Paraíba do Sul; Petrópolis, localizado na região serrana; Duque de Caxias e Magé, ambos inseridos na região metropolitana do Rio de Janeiro. O Rio Estrela serve, inclusive ao Sul, como limite natural entre os municípios de Magé e Duque de Caxias (Noronha, 1998).

Esta bacia possui como contribuintes os rios Estrela, Saracuruna e Inhomirim. O Rio Estrela, com $6 \mathrm{~km}$ de extensão, deságua na Baía de Guanabara. O Rio Saracuruna é o formador, pelo lado oeste, do Estrela e recebe como afluente, entre outros, o Canal de Imbariê. O Rio Inhomirim recebe as águas de alguns pequenos cursos como do rio Cachoeira e do Canal Caioaba, o qual foi construído para drenar as águas das enchentes, e hoje é utilizado como receptor de águas servidas (Noronha, 1998).

O elevado grau de urbanização ocorre, principalmente, nas áreas da parte média da bacia, mas também nas áreas mais baixas, onde os aterros estão cedendo lugar a uma crescente ocupação humana (Nowat \& Bundy,

2001). 


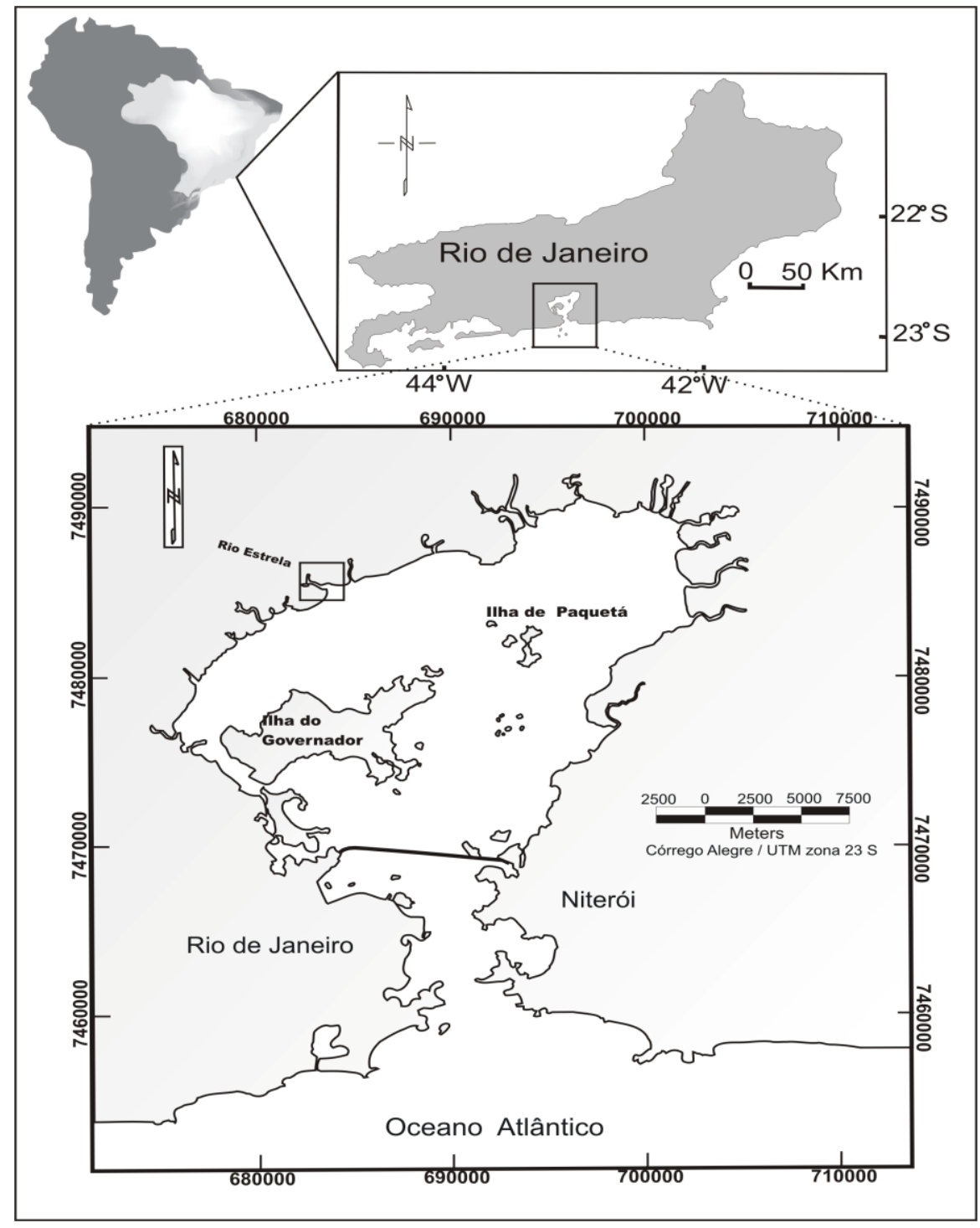

Figura 1: Mapa de localização da área de estudo

\section{METODOLOGIA ETAPA DE CAMPO}

$\mathrm{Na}$ campanha de campo foram coletadas amostras superficiais em dez pontos ao longo da bacia de drenagem do Rio Estrela, sendo que nos pontos mais profundos, a coleta foi realizada com um busca fundo do tipo Van Veen (Figura 2). Para o posicionamento foi utilizado um GPS Garmim Etrex de 12 canais. Os dados físico-químicos foram obtidos através da análise dos sedimentos in situ, com os respectivos instrumentos: $\mathrm{pH}$ metro portátil Perkin Elmer (modelo Q-400H), condutivímetro portátil Perkin Elmer(Q-405P) e oxímetro Perkin Elmer (Q-758 P). Os valores de temperaturas foram obtidos durante a coleta através de um termômetro de mercúrio simples. Os sedimentos foram armazenados em recipientes de vidro purificados e mantidos a uma temperatura estimada em $4^{\circ} \mathrm{C}$ antes de serem analisados em laboratório. 


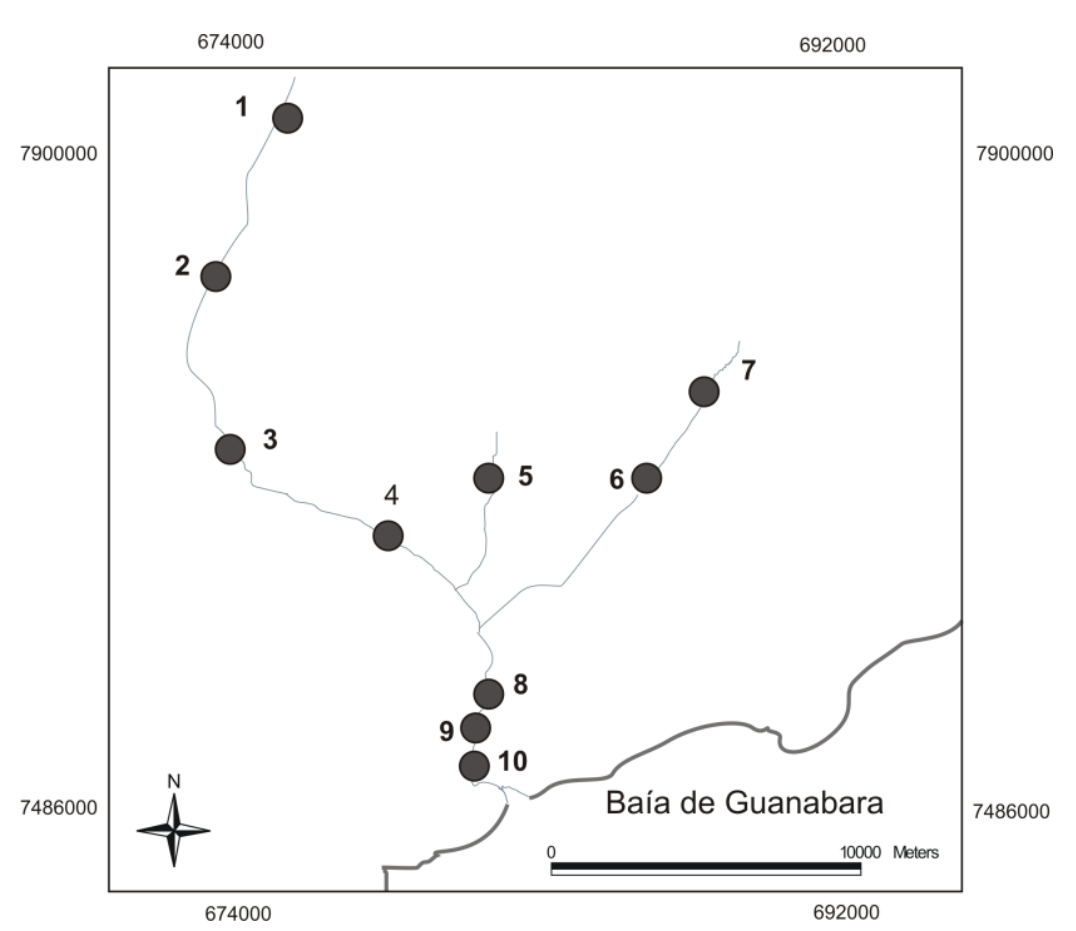

Figura 2: Mapa de localização da área de estudo com a localização das amostras superficiais

\section{ETAPA DE LABORATÓRIO}

A extração dos hidrocarbonetos nos sedimentos foi efetuada segundo os parâmetros do método EPA 3540C. Utilizou-se $10 \mathrm{~g}$ de sedimento úmido, misturado com $40 \mathrm{~g}$ de sulfato de sódio anidro. Posteriormente, executou-se a extração por 24 horas, com uma mistura de diclorometano-acetona. $\mathrm{O}$ volume do extrato passa pelo procedimento de redução em evaporador rotatório, sendo submetido à fase de fracionamento. Esta fração foi concentrada em evaporador rotativo a $1 \mathrm{ml}$ e encaminhado para a análise por cromatografia em fase gasosa acoplada a espectrometria de massas CG- (EM).

A determinação quantitativa e identificação dos HPAs foram realizadas em CG-(EM). O equipamento utilizado foi um cromatógrafo a gás modelo Hewlett Packard (HP) 5890, com detector seletivo de massa modelo 58971A. O manuseio e armazenagem dos dados analíticos foram realizados através de um software associado ao equipamento (HP Chemstation software).

\section{RESULTADOS E DISCUSSÕES PARÂMETROS FÍSICO-QUÍMICOS}

Os valores dos parâmetros físico-químicos obtidos através da análise da água in situ são bastante coerentes com as características físicas da área de estudo (Figura 3). Os pontos de coleta apresentaram valores de $\mathrm{pH}$ que variaram entre 5,67 e 7,18, sendo, desta forma, valores bem característicos de locais que possuem proporção significativa de matéria orgânica (Nowat \& Bundy, 2001). Supõe-se que os valores de $\mathrm{pH}$ nos pontos 8,9 e 10 ficaram acima de 7 , pelo aporte de água proveniente da baía, devido ao fato das coletas serem realizadas em um período de maré enchente influenciados portanto pelo efeito tampão da água do mar (Miranda et al., 2002).

Por sua vez, a salinidade medida no Rio Estrela apresentou o valor de 0,1 nos últimos 3 pontos de análise. Segundo (Esteves, 1998), águas salobras que apresentam salinidades menores que 0,5 são classificadas como água doce. As frações dissolvidas de oxigênio variaram entre 0,04 e 9,3 $\mathrm{mg} / \mathrm{l}$. Os menores valores de oxigênio dissolvido foram detectados nos 3 pontos determinados ao longo do Rio Estrela. Supõe-se que as baixíssimas concentrações constatadas neste rio ocorram devido à grande quantidade de matéria orgânica existente. Por se encontrar situado parcialmente em uma área de manguezal, é provável que no Rio 
Estrela, os processos de degradação da matéria orgânica associados à atividade bacteriana sejam responsáveis pelo intenso consumo deste oxigênio, resultando praticamente na inexistência de oxigênio dissolvido neste local (Botelho, 2003).

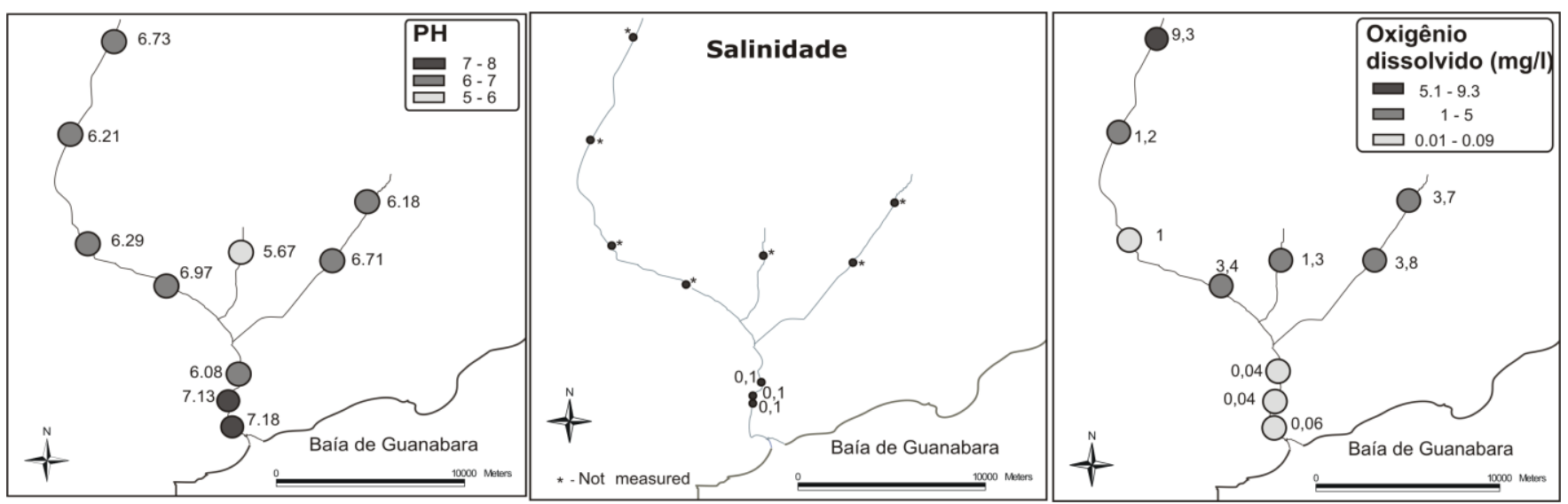

Figura 3: Mapas com os resultados dos parâmetros físico-químicos medidos na área

\section{GRANULOMETRIA}

A composição granulométrica dos sedimentos de fundo do Rio Estrela e afluentes varia de $11 \%$ à $95 \%$ de areia, 4 à $52 \%$ de silte e 1 à $37 \%$ de argila. Através das amostras plotadas no diagrama triangular de (Shepard, 1954) podese observar que os sedimentos destes rios mostram heterogeneidade textural e podem ser agrupadas nas seguintes classes: areia, areia siltosa, areia silte argila e silte argiloso (figura 4).

As classes areia e areia siltosa mostraramse proeminentes, onde a primeira ocorreu em cinco pontos e a segunda em três, enquanto a areia silte argila e o silte argiloso estiveram presente em um único ponto de coleta, respectivamente. É importante ressaltar que as maiores porcentagens de silte e argila ocorreram em pontos localizados no Rio Estrela e relativamente próximos à desembocadura onde a baixa energia hidrodinâmica determina a maior acumulação de material fino(Hozales-Hoz et al., 2003).

\section{MATÉRIA ORGÂNICA}

Os teores de matéria orgânica encontrados neste estudo apresentaram grandes variações entre os pontos de coleta, com um valor mínimo de $1,31 \%$ no ponto 1 , localizado próximo à nascente do rio Saracuruna, e um máximo de $16,36 \%$ no ponto 10, situado no Rio Estrela (Figura 4). O valor médio para todos os pontos foi de 5,99.

Em relação ao teor de matéria orgânica ao longo da bacia de drenagem, pode-se dizer que no Rio Saracuruna foram detectados baixos valores na concentração de matéria orgânica, com exceção do ponto 4 que apresentou uma porcentagem de $6,10 \%$, sendo portanto, um percentual ligeiramente mais elevado em relação aos valores constatados nos demais pontos deste rio. No ponto 5, localizado no Canal de Imbariê, pode-se visualizar uma concentração relativamente elevada: $9,35 \%$, se comparado com os demais pontos de coleta desta área. É provável que no ponto 5 , a intensa emissão de efluentes domésticos possa contribuir de forma significativa para o incremento na porcentagem de matéria orgânica, pois este canal possui um aspecto bastante degradado devido aos descartes antrópicos emitidos neste canal (Jaffé et al., 2003).

As estações 6 e 7, situadas no rio Inhomirim, apresentaram baixas concentrações com porcentagens de $3,49 \%$ e $1,88 \%$, respectivamente, enquanto os pontos determinados no Rio Estrela apresentaram as maiores porcentagens, principalmente no ponto 10 como já descrito e o ponto 8 , com o valor de $12,39 \%$, sendo considerados valores equiparados 
aos detectados por Baptista Neto et al. (2006) e colaboradores em áreas no interior da Baía de Guanabara, sendo alguns pontos deste trabalho citado bem próximos a desembocadura do Rio Estrela.

Provavelmente os pontos localizados no Rio Estrela e que possuem elevados teores de matéria orgânica, pontos 8 e 10, tenham estas concentrações acentuadas também por influência antrópica, pois próximo a esta área situa-se uma área desprovida de saneamento básico adequado e que possivelmente emite descartes domésticos para este ambiente.
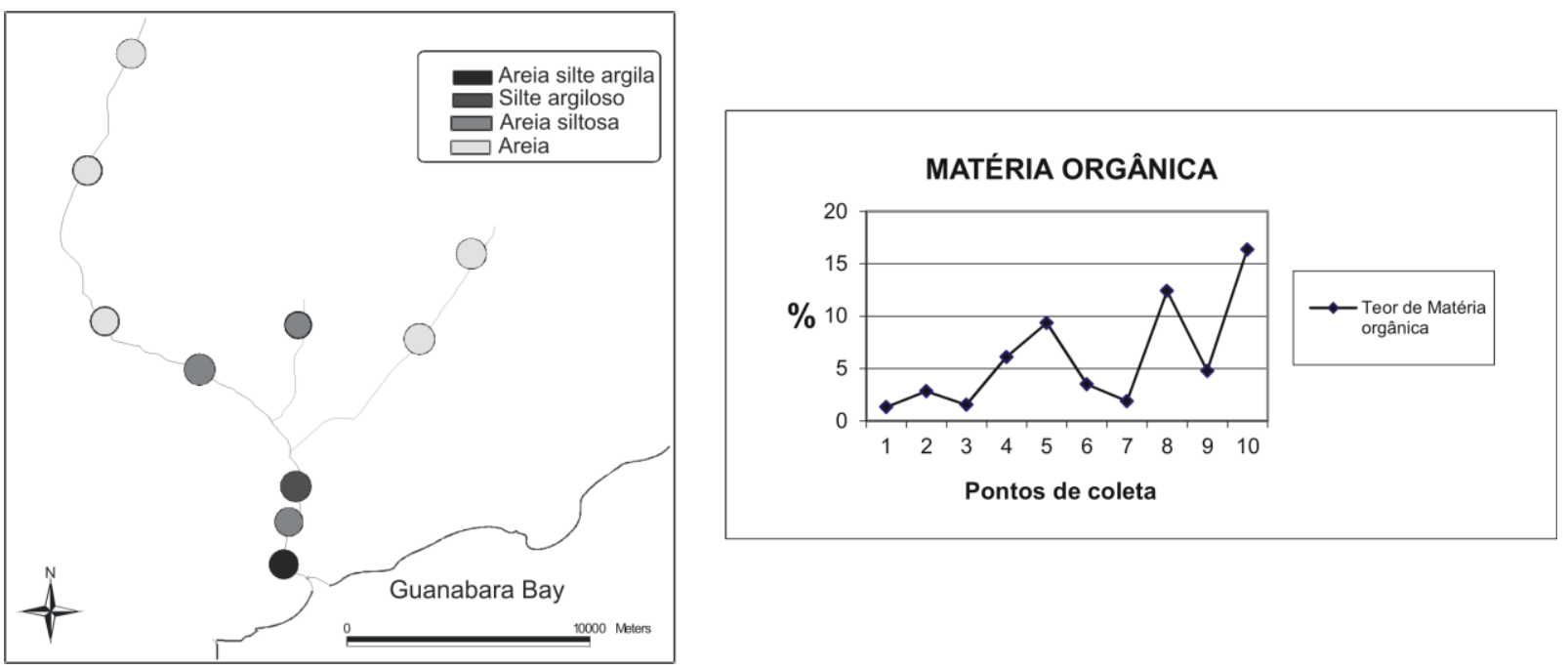

Figura 4: Mapa da relação de distribuição da granulometria e matéria orgânica na área estudada

\section{HIDROCARBONETOS POLICÍCLICOS AROMÁTICOS (HPAs)}

De um modo geral, os resultados de hidrocarbonetos se mostraram baixos. Dos 16 hidrocarbonetos policíclicos aromáticos (HPAs) analisados, considerados poluentes prioritários, somente 6 foram detectados.

Das dez estações de coleta, os HPAs estão presentes em somente 4 pontos da bacia de drenagem (figura 5). Os valores de concentração de HPAs ao longo da bacia de drenagem do Rio Estrela são considerados baixos, porém em proporções ligeiramente acentuadas quando comparadas com concentrações naturais, indicando, portanto emissões antrópicas de HPAs nesta área de estudo ( Boloubassi et al., 2005; Shi et al., 2005).

A concentração de HPAs totais variou de 0 a $0,09 \mathrm{mg} / \mathrm{kg}$. No Rio Estrela, dos 3 pontos de coletados determinados, a presença de HPAs foi detectada apenas no ponto 8, que apresentou uma concentração de $0,07 \mathrm{mg} / \mathrm{kg}$. O Rio Saracuruna apresentou os maiores valores de HPAs totais, onde foram encontrados nos pontos 2 e 4 valores de $0,08 \mathrm{mg} / \mathrm{kg}$ e $0,09 \mathrm{mg} / \mathrm{kg}$, respectivamente. No Rio Inhomirim e no Canal de Imbariê não se detectou a presença destes compostos nos pontos analisados.

Através do estudo realizado nos sedimentos coletados ficou evidente que os HPAs identificados são, em sua totalidade, de alto peso molecular que fazem parte da classe dos compostos que possuem de 4 a 5 anéis de benzeno em suas composições: fluoranteno, pireno, benzo(a) antraceno, benzo(b) fluoranteno e benzo(K) fluoranteno e criseno (Figura 5).

A distribuição dos HPAs na área é coincidente com os diferentes níveis de degradação dos rios na bacia de drenagem. Supõese que a concentração de HPAs no Rio Estrela, detectada no ponto 8 , ocorra devido à proximidade deste com a Refinaria Petroquímica de Duque de Caxias - RJ (REDUC), que possivelmente contribui com a emissão de partículas para este ponto, pois esta refinaria se localiza bem próxima a esta área. 

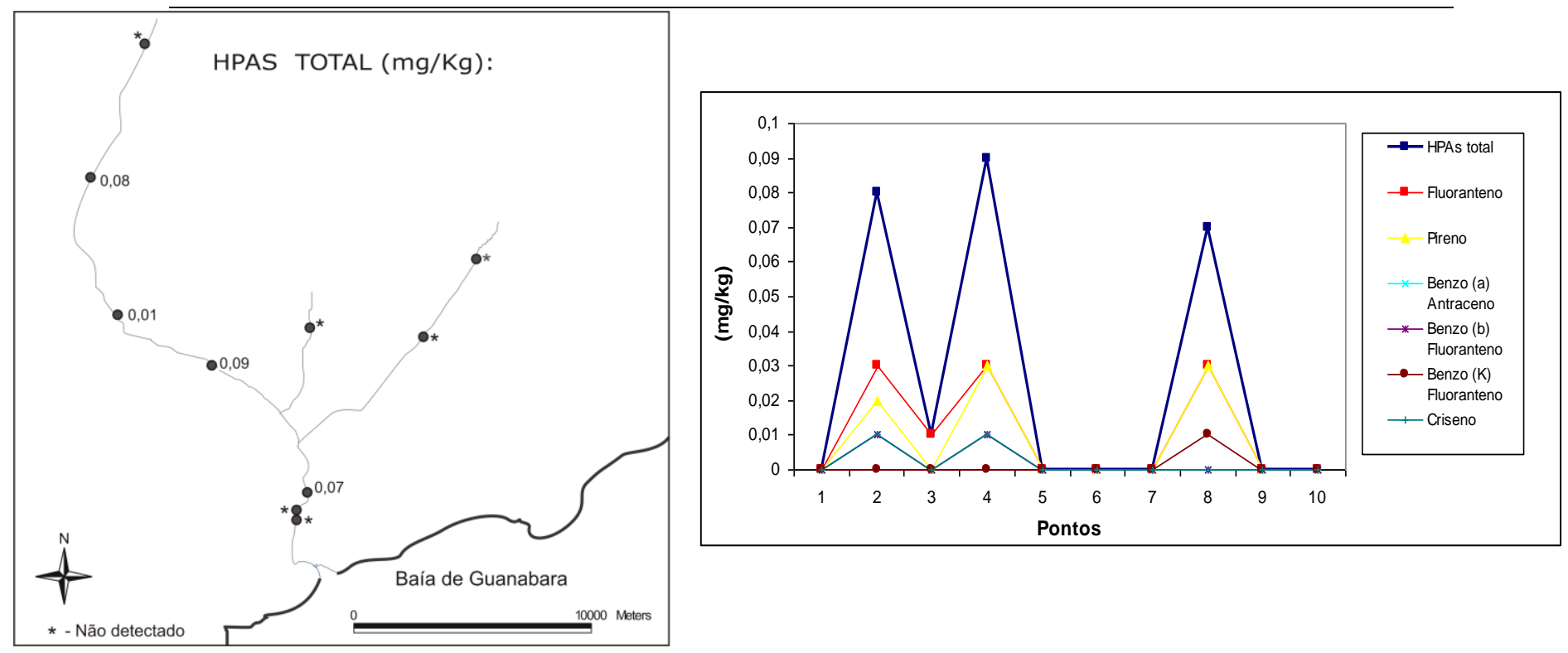

Figura 5: Concentrações e tipos de HPAs detectados ao longo da Bacia de drenagem do Rio Estrela em mg/kg.

O ponto 1 , localizado próximo à nascente do Rio Saracuruna, não apresentou a existência de HPAs, provavelmente pelo fato de estar localizado em uma área relativamente distante de possíveis fontes que pudessem emitir compostos de origem petrogênica ou derivados de combustão. No ponto 2, situado no centro comercial de Xerém, distrito de Duque de Caxias, se constatou a presença de HPAs. É possível que estes sejam provenientes da emissão particulada por veículos que circulam nas ruas e na principal avenida que estão situadas bem próximas ao Rio Saracuruna. O ponto 3, determinado próximo à Rodovia BR 040 apresentou somente a presença de fluoranteno, mesmo assim em concentração mínima: $0,01 \mathrm{mg} / \mathrm{kg}$, provavelmente depositados por veículos que circulam na rodovia. Na Rodovia RJ 116 (Rio-Teresópolis), os HPAs são possivelmente originários da emissão de partículas por veículos, abrasão de partículas do asfalto da rodovia, e possivelmente também pela deposição atmosférica da proximidade da REDUC, sendo estes tipos de fontes também constatadas em outros trabalhos ( Smith \& Levy, 1990; Wild \& Jones, 1995) .

Acredita-se que nos pontos 5, 6 e 7 a ausência dos HPAs pode ser atribuída principalmente ao fato de que estas últimas três áreas estão inseridas em uma região extremamente vazia demograficamente, principalmente no ponto 7. Supõe-se que a deposição atmosférica e abrasão de partículas de asfalto nos pontos 5 e 6 , mesmo sendo localizados próximos a rodovias não são suficientes para depositar HPAs de alto peso molecular em quantidades significativas que pudessem ser detectados (Torres et al., 2002).

A inexistência de HPAs de baixo peso molecular, tanto no Rio Estrela quanto nos seus afluentes, pode ser atribuída à atividade bacteriana existente, devido ao fato dos HPAs de baixo peso molecular serem altamente degradáveis em ambientes aquosos (Boloubassi et al., 2001).

Botelho (2003) realizou estudos para se detectar a ocorrência de HPAs na APA de Guapimirim e monitorou vários pontos ao longo do manguezal e de rios, e reportou concentrações que oscilaram entre 0,3 à $42,7 \mathrm{mg} / \mathrm{kg}$, apresentando portanto valores altos que provavelmente foram proporcionados pelo derramamento de óleo que ocorreu neste local em janeiro de 2000.

Em monitoramento nos sedimentos ao longo da Baía de Guanabara, Meniconi \& Gabardo (2002) detectaram a concentração máxima de $0,01 \mathrm{mg} / \mathrm{kg}$, sendo inferior à maior concentração obtida neste trabalho. As menores concentrações detectadas no trabalho citado acima podem ser atribuídas à hidrodinâmica de ambientes estuarinos que podem carrear estes poluentes, como HPAs depositados nos sedimentos superficiais e, portanto, influenciar na 
proporção de suas concentrações (Tam et al., 2001). Lima (1996) obteve as concentrações totais de HPAs ao longo do entorno da Baía de Guanabara e determinou grande parte dos pontos de coleta próximo à desembocadura de rios. $\mathrm{O}$ mesmo autor reportou as concentrações destes elementos com valores mínimo e máximo de 1,37 e $18,44 \mathrm{mg} / \mathrm{kg}$, e detectou HPAs tanto de baixo quanto de alto peso molecular.
Através da comparação do presente trabalho com estes estudos realizados na região da Baía de Guanabara, pode-se constatar que a bacia de drenagem do Rio Estrela apresentou valores de concentração total de HPAs extremamente inferiores em relação a outras áreas. Os valores das concentrações totais de HPAs obtidos no presente trabalho diferiram também em relação a outros estudos realizados em rios que se localizam em áreas similares (Tabela 1).

Tabela 1: Concentrações de HPAs na área de estudo comparados com os valores da literatura

\section{CORRELAÇÃO ESTATÍSTICA}

\begin{tabular}{lcl}
\hline \multicolumn{1}{c}{ Área de amostragem } & Concentrações $(\mathbf{m g} / \mathbf{k g})$ & \multicolumn{1}{c}{ Autores } \\
\hline Bacia do Rio Estrela & $0,00-0,09$ & Este estudo \\
Baía de Guanabara & $1,57-18,44$ & Lima (1996) \\
Baía de Guanabara & $0,0-0,01$ & Meniconi \& Gabardo ( 2002) \\
APA de Guapimirim (Baía de Guanabara) & $0,3-42,7$ & Botelho (2003) \\
Bacia de Tianjin- China & $0,01-0,5$ & Shi et al., (2005) \\
Canal de Saint John, Louisiana-USA & $0,12-78,73$ & Nowat \& Bundy (2001) \\
Canal Trepagnier, Louisiana -USA & $0,49-25,64$ & Nowat \& Bundy (2001) \\
Bacia do Rio Paraíba do Sul/Guandu & $1-40$ & Torres et al., (2002) \\
Delta do Niger, Nigéria & $2,1-7,2$ & Olajire et al., (2005) \\
\hline
\end{tabular}

O grau de correlação entre HPAs e outros parâmetros naturais é muitas vezes utilizado para se ter informações a respeito da dinâmica natural destes compostos. A matéria orgânica mostrou forte correlação com o silte e argila ( $p>0,900)$, confirmando a grande tendência de complexação. A matéria orgânica mostrou uma forte correlação com o silte e argila ( $p>0.9)$ e uma correlação inversamente proporcional à areia ( $\mathrm{p}>-0,9)$, confirmando a intensa afinidade entre compostos orgânicos e estas frações mais finas dos sedimentos ao longo deste sistema fluvial (Ahrens \& Depree, 2004). Uma significativa correlação entre HPAs total e teor de matéria orgânica nos sedimentos foi observada, confirmando a grande tendência de complexação entre HPAs e material orgânico nos sedimentos (Maranho et al., 2009; Yang et al., 2007).
Através da inversa correlação entre oxigênio dissolvido e salinidade ( $p>0,800$ ), obtidos nesta área de estudo, sugere que as concentrações de oxigênio dissolvido são bem mais influenciáveis pelo aporte fluvial do que pelo regime de marés que adentram o Rio Estrela. Os valores de correlação entre matéria orgânica e salinidade mostraram uma inversa correlação $(<0,600)$, confirmando a sobreposição do material orgânico carreado ao longo do sistema fluvial em detrimento da matéria orgânica transportada pelo fluxo salino trazido pelo regime de marés (Tabela 2). 
Tabela 2: Coeficiente de correlação de Pearson para HPAs nos sedimentos superficiais ao longo do Rio Estrela e afluentes

\begin{tabular}{|c|c|c|c|c|c|c|c|c|c|c|c|c|c|c|c|}
\hline & Areia & Silte & Argila & pH & Salinidade & OD & Temperatura & MO & HPAs total & Fluoranteno & Pireno & $\begin{array}{l}\text { Benzo (a) } \\
\text { antraceno }\end{array}$ & Criseno & $\begin{array}{l}\text { Benzo (b) } \\
\text { antraceno }\end{array}$ & $\begin{array}{l}\text { Benzo }(\mathbf{K}) \\
\text { antraceno }\end{array}$ \\
\hline Areia & 1 & & & & & & & & & & & & & & \\
\hline Silte & $-0,997$ & 1 & & & & & & & & & & & & & \\
\hline Argila & $-0,979$ & 0,976 & 1 & & & & & & & & & & & & \\
\hline pH & 0,03 & $-0,018$ & $-0,061$ & 1 & & & & & & & & & & & \\
\hline Sal & $-0,646$ & 0,648 & 0,648 & 0,342 & 1 & & & & & & & & & & \\
\hline OD & 0,578 & $-0,543$ & $-0,549$ & $-0,073$ & $-0,8$ & 1 & & & & & & & & & \\
\hline Temperatura & 0,36 & $-0,361$ & $-0,428$ & $-0,045$ & $-0,563$ & 0,406 & 1 & & & & & & & & \\
\hline MO & $-0,988$ & 0,985 & 0,967 & 0,067 & 0,646 & $-0,559$ & $-0,315$ & 1 & & & & & & & \\
\hline HPAs total & $-0,13$ & 0,106 & 0,055 & $-0,13$ & $-0,128$ & $-0,223$ & $-0,051$ & 0,068 & 1 & & & & & & \\
\hline Fluoranteno & $-0,173$ & 0,15 & 0,097 & $-0,215$ & $-0,043$ & $-0,303$ & $-0,103$ & 0,097 & 0,984 & 1 & & & & & \\
\hline Pireno & $-0,405$ & 0,406 & 0,346 & $-0,172$ & 0,094 & $-0,237$ & $-0,306$ & 0,322 & 0,886 & 0,9 & 1 & & & & \\
\hline $\begin{array}{l}\text { Benzo (a) } \\
\text { antraceno }\end{array}$ & $-0,405$ & 0,406 & 0,346 & $-0,172$ & 0,094 & $-0,237$ & $-0,306$ & 0,322 & 0,886 & 0,9 & 1 & 1 & & & \\
\hline Criseno & 0 & 0 & $-0,087$ & 0,087 & $-0,327$ & 0,087 & 0 & 0 & 0,784 & 0,697 & 0,699 & 0,699 & 1 & & \\
\hline $\begin{array}{l}\text { Benzo (b) } \\
\text { antraceno }\end{array}$ & 0 & 0 & $-0,087$ & 0,087 & $-0,327$ & 0,087 & 0 & 0 & 0,784 & 0,697 & 0,699 & 0,699 & 1 & 1 & \\
\hline $\begin{array}{l}\text { Benzo }(K) \\
\text { antraceno }\end{array}$ & $-0,522$ & 0,524 & 0,524 & $-0,406$ & 0,509 & $-0,466$ & $-0,43$ & 0,406 & 0,327 & 0,465 & 0,574 & 0,574 & $-0,167$ & $-0,167$ & 1 \\
\hline
\end{tabular}




\section{CONCLUSÕES}

Os resultados obtidos de concentrações de hidrocarbonetos poliaromáticos (HPAs) na Bacia de drenagem do Rio Estrela, mostraram-se extremamente baixos se comparados a outras áreas que também possuem urbanização significativa. HPAs de baixo peso molecular não foram detectados ao longo da área de estudo, provavelmente pela ausência de fontes emissoras ou pela ocorrência destes em pequenas facilmente degradáveis pela atividade bacteriana.

Constatou-se que as concentrações de HPAs dos sedimentos na bacia de drenagem do rio Estrela são baixas. Analisando os dados obtidos, pode-se constatar que a bacia de drenagem não contribui de forma significativa para a emissão de HPAs para a Baía de Guanabara através do aporte sedimentar do Rio Estrela e seus afluentes. Porém, é necessário dar continuidade na realização de pesquisas científicas nos rios deste local para se observar possíveis oscilações em relação à emissão destes poluentes, pois as condições ambientais são mutáveis e precisam ser monitoradas.

\section{NOTAS}

${ }^{1}$ Doutor em Geologia e Geofísica Marinha pela Universidade Federal Fluminense (UFF). Pós Doutorando no Departamento de Geologia / LAGEMAR - UFF. Contato: marclei@igeo.uff.br

${ }^{2}$ Doutor em Geografia Física pela Queen's University of Belfast - UK. Professor Adjunto da Universidade Federal Fluminense - UFF.

${ }^{3}$ Doutor em Geologia e Geofísica Marinha pela Universidade Federal Fluminense (UFF). Pós Doutorando no Departamento de Geologia / LAGEMAR - UFF.

\section{REFERÊNCIAS}

AHRENS, M.J.; DEPREE, C.V. (2004) Inhomogeneous distribution of polycyclic aromatic hydrocarbons in different size and density fractions of contaminated sediment from Auckland Habour, New Zealand: an opportunity. Marine Pollution Bulletin 48: 341-350.

BOTELHO, A. L. M. Análise da contaminação por óleo na APA de Guapimirim - RJ. Aspectos Geoquímicos e Sócio-ambientais. Dissertação de Mestrado. Departamento de Ciência Ambiental. Universidade Federal Fluminense, Niterói, RJ. 100 pp, 2003.

BOULOBASSI, I.; FILLAUX, J.; SALIOT, A. Hydrocarbons in surface sediments from the Changjiang (Yangtze River) Estuary, East China Sea, Marine Pollution Bulletin 42 (12), 1335, 2001.

CHRISTENSEN, E. R.; BZUSECK, P. A. PAHs in sediments of the Black river and the Ashtabula river, Ohio: source apportionmentby factor analysis. Water research. 39, 511-524, 2005.

ESTÈBE, A.; BOUDRIES, H.; MOUCHEL, J. M., THÈVENOT, D.R. Urban runoff impacts on particulate metals and hydrocarbon concentrations in river Seine: Suspended solid and sediment transport. Water Sci. Technol. 36, 185-193, 1997.

ESTEVES, F.A. Fundamentos de limnologia. $2^{\mathrm{a}}$ ed. Rio de Janeiro, Interciência. 602p, 1998.

HOZALES-HOZ, L.; CUNDY, A.B.; BAHENA-MANJARREZ, J.L. Heavy metals in sediment cores from a tropical estuary affected by anthropogenic discharges: Coatzacoalcos estuary, Mexico. Estuarine Coastal and Shelf Science. 58, 117-126, 2003.

JAFFÉ，R.; GARDINALI，P.R.; CAÍ Y.; SUDBURRY, A.; FERNANDEZ, A.; HAY, B.J. Organic compounds and trace metals of anthropogenic origin in sediments from Montego Bay, Jamaica: assessment of sources and distribution pathways. Environmental Pollution. 123, 291-299, 2003. 
KJERVE, B.; RIBEIRO, C.H.A.; DIAS, G.T.M.; Filipo, A. M.; QUARESMA, V. S. Oceanographic characteristics of na impacted coastal bay: Baia de Guanabara, Rio de Janeiro, Brazil. Continental Shelf Research. 17(13): 1609-1643, 1997.

LIMA, A.L.C. Geocronologia de hidrocarbonetos poliaromáticos (HPAs) Estudo de caso: Baía de Guanabara. Dissertação de Mestrado. Departamento de Química, Pontifícia Universidade Católica do Rio de Janeiro, Rio de Janeiro.100pp, 1996.

MARANHO, L.A.; ABREU, I.; SANTELLI, R.; CORDEIRO, R.C.; SOARES-GOMES, A.; MOREIRAS, L.B.; MORAIS, R.D.; ABESSA, D.M. Sediment toxicity assesment of Guanabara Bay, Rio de Janeiro, Brazil. Journal of Coastal Research. 56: 851-855, 2009.

MENICONI, M.F.G. and GABARDO, I.T. Brazilian oil spills chemical characterization Case Studies. Environmental Forensis. 3: 303321. 2002.

MIRANDA, L.B.; CASTRO, B.M.; KJERVE, B. Princípios de Oceanografia Física de Estuários.USP: São Paulo, SP, Brasil, 2002.

NORONHA, A.L.R. A Bacia do Rio Estrela: Subsídios ao Monitoramento Ambiental da Baía de Guanabara. Dissertação de Mestrado. Instituto de Geociências - Univerdidade Federal do Rio de Janeiro, Rio de Janeiro.119p, 1998.

NOWAT, F.S.; BUNDY K. J. Correlation of field-measured toxicity with chemical concentration and pollutant availability. Environment International. 27, 479- 489, 2001.

OLAJIRE, A.A.; ALTENBURGER, R.; KÜSTER, E.; BRACK, W. Chemical and ecotoxicological assessment of polycyclic aromatic hydrocarbon -contaminated sediments of the Niger Delta, Southern Nigeria. Science Total Environment, 340 (1$3)$ 123-36. DOI: 10.1016/j.scitotenv. 2004.08.014, 2005.

SHEPARD, F.P.Nomenclature based on sandsilt-clay ratios. Journal of Sedimentary Petrology,24:151-158, 1954.

SHI, Z.; TAO, S.; PAN, B.; FAN, W.; HE, X.C.; ZUO, Q.; WU, S.P.; LI, B.G., CAO, J.; LIU, W. X.; XU, F.L.; WANG, X.J.; SHEN, W.R.; WONG, P.K.Contamination of rivers in Tianjin, China by polycyclic aromatic hydrocarbons. Environmental Pollution. 134, 97-111, 2005.

SMITH, J.N.; LEVY, E.M.Geochronology for polycyclic aromatic hydrocarbon contamination in sediments of the Saguenay Fjord. Environmental Science Technology. 24 (6), 874 -879, 1990.

TAM, N.F.Y.; Ke, L.; WANG, X.H. \& WONG, Y.S.Contamination of polycyclic aromatic hydrocarbons in surface sediments of mangrove swamps. Environmental Pollution. 114, 255-263, 2001.

TORRES， J.P.M.; MALM， O.; VIEIRA, E.D.R.; JAPENGA，J.;KOOPMANS， G.F. Organic micropollutants on river sediments from Rio de Janeiro, Southeast Brazil, Caderno de Saúde Pública, 18 (2): 477-488, 2002.

WILD, S.R.; JONES, K.C. Polynuclear aromatic hydrocarbons in the Kingdom environment. A preliminary source inventory and budget. Environmental Pollution. 88: 91108, 1995.

WITT, G.; TROST, E. Polycyclic aromatic hydrocarbons (HPAs) in sediments of the Baltic Sea and of the German coastal waters. Chemosphere 38, 1603-1614, 1999. 
YANG, Y.; LIGOUIS , B.; PIES, C.; GRATHWOHL, P.; HOFMANN, T.

Occurrence of coal and coal-derived particle bound polycyclic aromatic hydrocarbons (PAHs) in a river floodplain soil. Environmental Pollution.151 (1): 121-9, 2007.

YUAN, S.Y.; CHANG, J.S.; YEN, J.H.; CHANG, B.V. Biodegradation of phenanthrene in river sediment. Chemosphere 43, 273-278. 2001. 